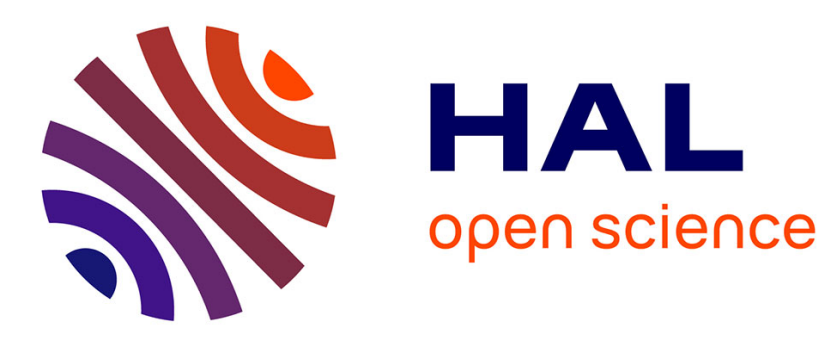

\title{
Design and Modeling of an Upper Extremity Exoskeleton
}

Salam Moubarak, Minh Tu Pham, Thomas Pajdla, Tanneguy Redarce

\section{To cite this version:}

Salam Moubarak, Minh Tu Pham, Thomas Pajdla, Tanneguy Redarce. Design and Modeling of an Upper Extremity Exoskeleton. 11th International Congress of the IUPESM : medical physics and biomedical engineering world congress 2009, Sep 2009, Munich, Germany. pp.476-479. hal-00443902

\section{HAL Id: hal-00443902 \\ https://hal.science/hal-00443902}

Submitted on 5 Jan 2010

HAL is a multi-disciplinary open access archive for the deposit and dissemination of scientific research documents, whether they are published or not. The documents may come from teaching and research institutions in France or abroad, or from public or private research centers.
L'archive ouverte pluridisciplinaire HAL, est destinée au dépôt et à la diffusion de documents scientifiques de niveau recherche, publiés ou non, émanant des établissements d'enseignement et de recherche français ou étrangers, des laboratoires publics ou privés. 


\title{
Design and Modeling of an Upper Extremity Exoskeleton
}

\author{
S. Moubarak ${ }^{1}$, M.T. Pham ${ }^{1}$, T. Pajdla ${ }^{2}$ and T. Redarce ${ }^{1}$ \\ ${ }^{1}$ Laboratoire Ampere UMR CNRS 5005, INSA-Lyon, F-69621, France \\ ${ }^{2}$ Czech Technical University Prague, Department of Cybernetics, Center of Machine Perception, Czech Republic
}

\begin{abstract}
This paper presents the design and modeling results of an upper extremity exoskeleton mounted on a wheel chair. This new device is dedicated to regular and efficient rehabilitation training for weak and injured people without the continuous presence of a therapist. The exoskeleton being a wearable robotic device attached to the human arm, the user provides information signals to the controller in order to generate the appropriate control signals for different training strategies and paradigms. This upper extremity exoskeleton covers four basic degrees of freedom of the shoulder and the elbow joints with three additional adaptability degrees of freedom in order to match the arm anatomy of different users.
\end{abstract}

Keywords - Upper extremity exoskeleton, medical robotics, rehabilitation.

\section{INTRODUCTION}

Elderly people, stroke victims, hemiplegic subjects, paralyzed and spinal cord injured persons suffer from many forms of handicaps for locomotion because of the decline of their physical and muscular strength. Robotic assistance and rehabilitative training have recently become more common, and thus, commercial robotic devices and orthosis are already available and increasingly needed to assist, facilitate and accelerate the training and the recovery of weak and injured people.

Several studies have been carried out on robotic medical training and assistance. For lower limbs, these works not only concentrated on the therapeutic applications of the robotic devices, but also on the development of lower extremity exoskeletons for the augmentation of the load carrying capability and the endurance of the user [1]. However, for the upper limbs, most researchers have paid increasing attention to develop upper extremity exoskeletons for medical assistance and rehabilitation training [2]-[6].

This paper deals with the development and the modeling of an upper extremity exoskeleton mounted on a wheel chair (Fig. 1). Our objectives are to provide an efficient rehabilitative training and physiotherapy for the patient's arm, as well as the possibility for the therapist to apply different training strategies with a variable assistance degree depending on the state of the user and the injury level. Furthermore, this device enables the patient to have a consistent training without the continuous assistance of the therapist; therefore, the latter can work on many patients simultaneously and the total cost of the therapy can be reduced.

The paper is organized as follows: Section 2 deals with the human arm anatomy. Section 3 describes the different components of our prototype. Section 4 presents the kinematic and dynamic modeling of the exoskeleton. Finally, a brief conclusion highlights the ongoing works but also the perspectives of this project.

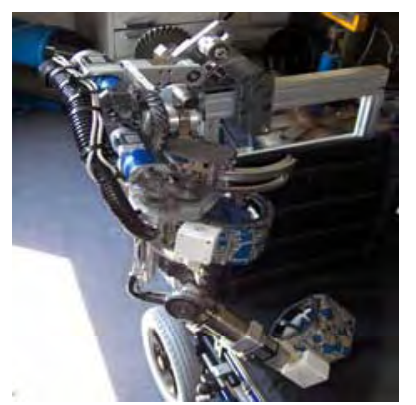

Fig. 1 The upper extremity exoskeleton

\section{HumAN ARM ANATOMY}

The shoulder and elbow gather 5 bones of the upper limb: the clavicle, the scapula, the humerus, the ulna and the radius [6] (Fig. 2).

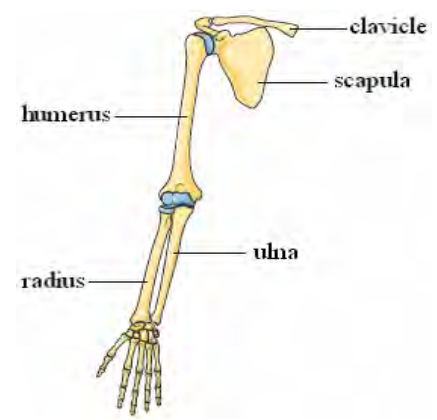

Fig. 2 The shoulder and elbow bones

From a biomechanical point of view, the human anatomy can be represented as a set of rigid bodies connected by joints. In robotic rehabilitation, biomechanical models can be used for the design as well as the control of the prototype 
to simplify the interaction mechanism between the human and the robot. Mechanical analyses are carried out to validate the kinematic structure of the robot and its actuators dimensions.

Biomechanical models of the upper limb are also used for evaluation and diagnosis, in order to control the forces and the couples generated by the upper limb movements during a robotic assisted rehabilitation session.

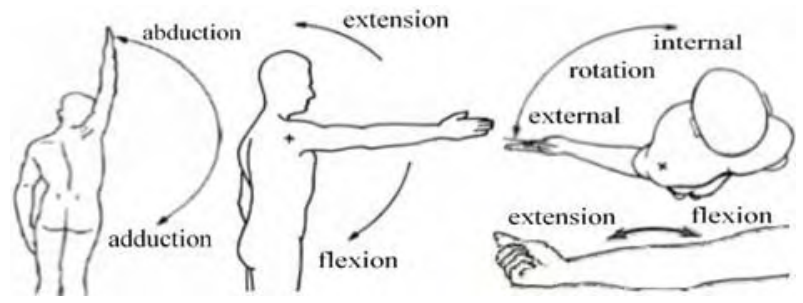

Fig. 3 The four basic degrees of freedom of the arm

The human arm has three complex articulations; the shoulder, the elbow and the wrist. Our prototype, being dedicated to the shoulder and elbow rehabilitation training, covers three shoulder degrees of freedom (DoFs) (abduction / adduction, flexion / extension and internal / external rotation) and one elbow DoF (flexion / extension) (Fig. 3).

Table 1 Human arm characteristics

\begin{tabular}{|l|c|c|c|c|}
\hline & $\begin{array}{c}\text { Shoulder } \\
\text { adduction }\end{array}$ & $\begin{array}{c}\text { Shoulder } \\
\text { flexion }\end{array}$ & $\begin{array}{c}\text { Shoulder } \\
\text { rotation }\end{array}$ & $\begin{array}{c}\text { Elbow } \\
\text { flexion }\end{array}$ \\
\hline Range of motion & $0^{\circ}-180^{\circ}$ & $-50^{\circ}-180^{\circ}$ & $-80^{\circ}-100^{\circ}$ & $0^{\circ}-145^{\circ}$ \\
\hline
\end{tabular}

Table 1 gives the average range of the shoulder and the elbow joints of the human arm [6].

\section{A NEW UPPER EXTREMITY EXOSKELETON}

This section describes the three prototype's components:

-The mechanical structure

-The actuators and the force sensors

-The control system

The prototype has 4 motorized degrees of freedom; the shoulder abduction / adduction, flexion / extension and internal / external rotation as well as the elbow flexion / extension motion. The shoulder height, the shoulder width and the arm length can be adapted to fit with different body sizes for different users. An arm holder and a wrist holder with 8 integrated force sensors are sending information signals to the controller in order to estimate the state of the user and his motion intentions. Each motor is connected to a drive and can be controlled either by torque or by velocity.
The 4 drives, the force sensors and the adaptability motors are connected to a Dspace card and continuously exchanging information and control signals. Different control schemes can be created and applied using Matlab / Simulink and Dspace -Control Desk interface.

\section{III.1- Mechanical structure:}

The main purpose of an exoskeleton is not only to provide efficient motion assistance to the human limbs, but also to guarantee the safety and the comfort of the user. That is why matching the human body anatomy is one of the most important criteria for an exoskeleton design.
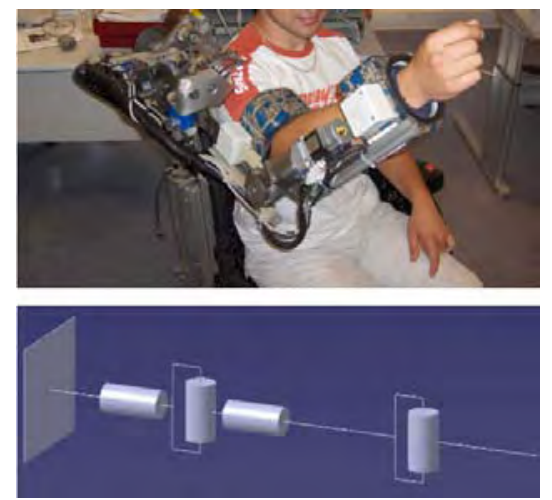

Fig. 4 The mechanical structure of the exoskeleton

The mechanical structure of our prototype (Fig. 4) mainly consists of three links and four revolute joints covering the basic degrees of freedom of the human arm. The motion range of the robot's joints is limited to provide a wide risk-free workspace for the user. The arm is attached to the exoskeleton by external arm and wrist holders with pressure adjustable internal pneumatic holders. The rotation motion is transmitted from the motor axes to the joint axes by rigid and compact spiro-conical gear systems. The prototype is relatively lightweight $(10 \mathrm{Kg})$ with a high ratio of DoFs / weight (Fig. 5).
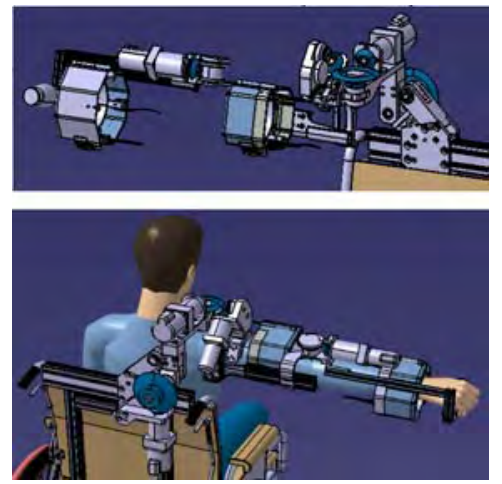

Fig. 5 The gear systems and the arm holders of the exoskeleton 


\section{III.2- Actuators and force sensors:}

The four active DoFs of the prototype are motorized by brushless motors with high torque and relatively small dimensions. The motor torques are amplified by the reducers and the gear systems, to give final output torques of $63 \mathrm{Nm}$ for the shoulder abduction / adduction, $52.5 \mathrm{Nm}$ for the shoulder flexion / extension, $17.1 \mathrm{Nm}$ for the shoulder internal / external rotation, and $13.5 \mathrm{Nm}$ for the elbow flexion / extension motion.

The prototype must be adaptable so it can be used by different patients with different body sizes. The shoulder height, the shoulder width and the arm length can be varied using three DC motors to fit with the users' body dimensions.

The control of the prototype with different training strategies is mainly based on the information feedback signals from the user and the exoskeleton. The motor encoders' feedbacks provide a real time estimation of the position and the velocity of the joints and can be used as feedback information for the kinematic and dynamic models. However, to control an exoskeleton for medical and rehabilitation applications, we need to estimate the state of the user, his interactions with the robot and sometimes we need to predict his motion intentions in order to apply the appropriate robotic assistance. One solution consists in using force sensors. Therefore, depending on the training strategy, we can guide the patient's arm in the correct displacement or modify the exoskeleton's motion to assist him in his desired motion.

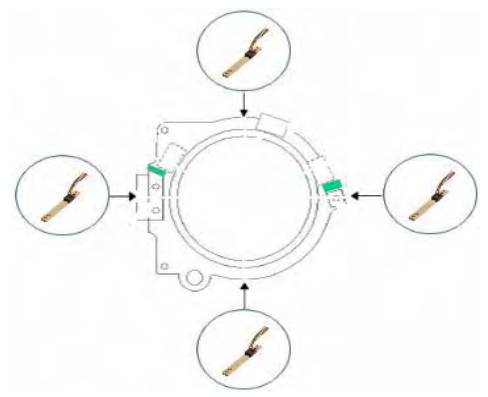

Fig. 6 The arm holder with the force sensors

In our prototype, 4 force sensors are applied in each arm holder. Each sensor can measure any force in the $0-125 \mathrm{~N}$ interval. The sensors are surrounding the arm and the wrist at $90^{\circ}$ on from the other, detecting almost all the possible interactions between the user and the robot (Fig. 6).

\section{III.3- Control system:}

All brushless motors are equipped with high resolution magnetic encoders for position feedback measurements. Each motor is connected to a drive with a sampling frequency of $5 \mathrm{KHz}$. The 4 drives, the 3 adaptability DC motors and the 8 force sensors are connected to the same electronic interface card.

The electronic card exchanges information and control signals with a Dspace controller analyzing all the feedback information and sending the appropriate control signals to the system depending on the training strategy. At this stage, different control schemes and therapy modes are created and applied to the system using Matlab / Simulink software and Controldesk interface.

The complete electrical setup diagram of the system is shown in Fig. 7.

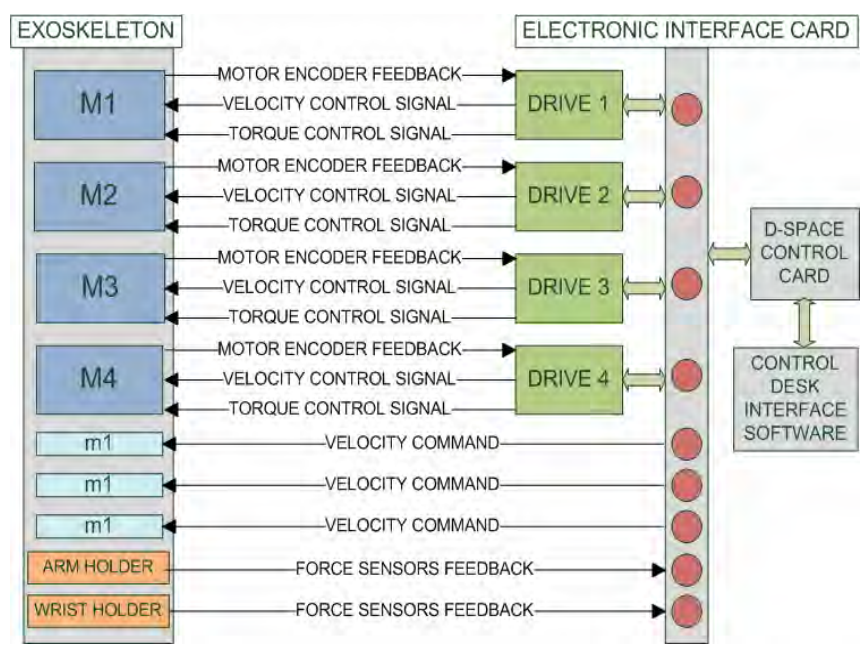

Fig. 7 The electrical setup

\section{Modeling OF THE EXoskeleton}

In order to achieve a compliant controller for the exoskeleton, the kinematic and dynamic models of the structure must be calculated and identification experiments must be carried out to get a better estimation of the dynamic and friction parameters of the robot, and therefore, improve the theoretical models.

\section{IV.1- Geometric and inertial parameters:}

The mechanical structure of our prototype mainly consists of three links and four joints. The geometric parameters of the robot have been calculated using the Denavit-Hartenberg notations.

The theoretical inertial parameters, used in the dynamic modeling have been calculated based on a complete CATIA model of the prototype.

\section{IV.1- Kinematic and dynamic models:}

The following models have been calculated using SYMORO+ software (Symbolic Modeling of Robots) and simulated with Matlab/Simulink interface [7]: 
- The direct kinematic model (DKM)

- The inverse kinematic model (IKM)

- The direct differential kinematic model (DDKM)

- The inverse differential kinematic model (IDKM)

- The direct dynamic model (DDM)

- The inverse dynamic model (IDM)

The simulation diagram of the kinematic and dynamic models is shown in fig. 8.

A motion generator $(\mathrm{MG})$ creates, for each joint, a $5^{\text {th }}$ degree displacement between two given positions, in a given time, starting and ending with a null acceleration.

$q, \dot{q}$ and $\ddot{q}$ represent the joint position, velocity and acceleration vectors created by the motion generator.

$X, \dot{X}$ and $\Gamma$ represent the final link position and velocity vectors and the joints torque vector calculated by the direct models.

$Q, \dot{Q}$ and $\ddot{Q}$ represent the joint position, velocity and acceleration vectors calculated by the inverse models.

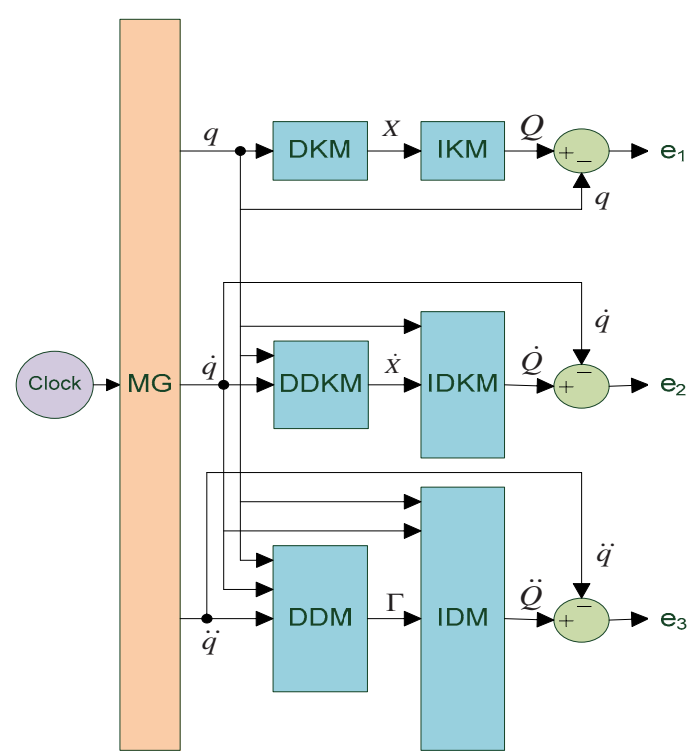

Fig. 8 The modeling and simulation diagram

The six kinematic and dynamic models have been simulated and validated $\left(\mathrm{e}_{1}=\mathrm{e}_{2}=\mathrm{e}_{3}=0\right)$.

An important criterion for comfortable rehabilitation training is the efficient gravity compensation of the prototype so that the user can move his arm freely without feeling the mass of the robot. The static component of the inverse dynamic model is applied on the prototype and $90 \%$ of the gravity effect of the exoskeleton has been compensated successfully.
Identification experiments are being carried out in order to improve the theoretical estimations of the inertial and the friction parameters of the exoskeleton.

\section{CONCLUSION AND FURTHER WORKS}

This paper introduces the design and modeling results of an upper extremity exoskeleton mounted on a wheel chair. The key objective of this device is to help users with disabled upper limbs to practice their daily living activities by providing different training levels and therapy modes. It can accelerate the muscle strength development and the recovery of post-stroke and spinal cord injured persons, as well as accident victims and elderly people.

The direct and inverse kinematic, differential kinematic and dynamic models of our prototype have been created based on the Denavit-Hartenberg notations, calculated using SYMORO+ software, simulated and validated with Matlab/Simulink interface.

Another aspect of this work concerns the control strategy. The force sensors feedback will be used in order to estimate the state and the motion intentions of the user; and create efficient training strategies and therapy modes for a better and faster recovery.

\section{AcKNOWLEDGMent}

This work was supported by EC project MEST-CT-2005-021024 WARTHE.

\section{REFERENCES}

1. R. Steger, S.H. Kim, H. Kazerooni, "Control scheme and networked control Architecture for the Berkeley lower extremity exoskeleton (BLEEX)", IEEE International conference on robotics and automation, Orlando, Florida, Mai 2006, pp.3469-3476.

2. E. Rocon, A.F. Ruiz, F. Brunetti, and J.L. Pons, "On the use of an active wearable exoskeleton for tremor suppression via biomechanical loading", IEEE International conference on robotics and automation, Orlando, Florida, Mai 2006, pp.3140-3145.

3. K. Kiguchi, Y. Imada, and M. Lianage, "EMG-Based Neuro-Fuzzy Control of a 4DOF power-assist exoskeleton", 29th IEEE EMBS International conference, Cité internationale, Lyon, France, August 2007, pp.3040-3043.

4. R. Song, K.Y. Tong, X.L. Hu, S.F. Tsang, and L. Li, "The therapeutic effects of myoelectrically controlled robotic system for persons after stroke-A pilot study ", 28th IEEE EMBS International conference, New York city, USA, August-September 2006, pp.3504-3511.

5. M. Mihelj, T. Nef, and R. Reiner, "ARMin II-7DOF rehabilitation robot: mechanics and kinematics", IEEE International conference on robotics and automation, Romania, Italy, April 2007, pp.4120-4125.

6. A. Denève, "Développement et commande d'un robot pour la rééducation des membres supérieurs", Ph.D. dissertation, University of Reims Champagne-Ardenne, France, 2007.

7. W. Khalil, E. Dombre, "Modélisation, identification et commande des robots", PARIS, Hermès, 1999. 